\title{
Visualization and Measurement of Water Distribution in Through-Plane Direction of Polymer Electrolyte Fuel Cell during Start-Up by Using Neutron Radiography
}

\author{
Hideki Murakawa', Katsumi Sugimoto', Nobuki Kitamura1, Hitoshi Asano', \\ Nobuyuki Takenaka1, Yasushi Saito ${ }^{2}$ \\ ${ }^{1}$ Department of Mechanical Engineering, Graduate School of Engineering, Kobe University, Kobe, Japan \\ ${ }^{2}$ Research Reactor Institute, Kyoto University, Osaka, Japan \\ Email: murakawa@mech.kobe-u.ac.jp
}

Received 25 March 2015; accepted 23 June 2015; published 30 July 2015

Copyright (C) 2015 by authors and Scientific Research Publishing Inc.

This work is licensed under the Creative Commons Attribution International License (CC BY).

http://creativecommons.org/licenses/by/4.0/

(c) (i) Open Access

\begin{abstract}
Water management in a polymer electrolyte fuel cell (PEFC) is a key topic for PEFC operation. A microporous layer (MPL) has been recently used to improve the water flooding in the gas diffusion layer (GDL) around the catalyst layer. However, the mechanisms of this MPL are not completely understood because of the difficulty of measuring the water distribution during operation. To clarify the water-accumulation phenomena with the MPL, visualization and measurement of the water distribution in the through-plane direction of a small fuel cell is carried out by using neutron radiography. The parallelism of the neutron flux is optimized by using a collimator to observe the transient change in the water distributions, and two-dimensional water distributions in the through-plane direction of the PEFC can be obtained every $60 \mathrm{~s}$. The differences in the water accumulation processes in the GDL without and with the MPL under the lands and channels are compared. It is observed that the water accumulation in the GDL under the land is greater than that under the channel during the period of early PEFC operation. Water evacuation from the GDL to the channel mainly occurs around the land corners. Furthermore, one-dimensional water distributions are calculated from the visualized water distributions, and the results without and with the MPL in the cathode are compared. The water thickness in the through-plane direction attains its maximum value around the boundary between the catalyst layer and the GDL without the MPL, whereas it is attained between the MPL and the GDL with the MPL. The maximum water accumulation in the GDL under the land without the MPL is higher than that with the MPL.
\end{abstract}




\section{Keywords}

\section{PEFC, Microporous Layer, Water Distribution, Neutron Radiography}

\section{Introduction}

A polymer electrolyte fuel cell (PEFC) consists of a proton exchange membrane (PEM) sandwiched between gas diffusion layers (GDLs) and separator plates, as shown in Figure 1. Fuel gas (hydrogen gas) and oxidant gas (air) are supplied to the PEFC from the gas channels. The GDL is a porous medium being made of carbon fibers. At the anode, protons and electrons are generated, whereas the protons and electrons recombine at the cathode to form water. Condensation may be occurred on the cathode side because the vapor is supersaturated by the fuel-cell reactions. When condensed water exists in the GDL, gas diffusion is depressed as flooding. Furthermore, a larger amount of water in the gas channels may prevent the gas supply in the channel, and the cell performance decreases because oxygen is prevented from reaching the cathode reaction site. On the other hand, the generated water must be appropriately supplied to the PEM for proton conduction. Hence, water management is significantly important for PEFC performance, and clarification of the water-transport mechanisms between the PEM, GDL, and gas channels is of great concern. Many investigations on water management have been carried out concerning water movement inside the PEM, water flooding in the GDL, and water plugging in the channel [1]-[3].

A microporous layer (MPL) with a pore size that ranges from 0.1 to $0.5 \mu \mathrm{m}$ [1], which normally consists of carbon black with a polytetrafluoroethylene (PTFE) binder, has been widely used in PEFCs recently. It is well known that the MPL improves the water evacuation from the GDL. For understanding the effect of the MPL on the water-transport mechanism, many investigations have been carried out. It is reported that a thicker MPL exhibits better PEFC performance [4] [5]. Markötter et al. [6] [7] measured the water transport across the GDL and MPL by using X-ray radiography and showed the details of liquid-water transfer through the GDL using a PEFC with an observation hole. They showed that MPL cracks played a significant role in liquid-water transport. Deevanhxay et al. [8] used soft X-rays to show that water was transported from the reaction site mainly through cracks in the MPL. Kim et al. [9] investigated the effect of the MPL arrangement on the electrochemical losses by using electrochemical impedance spectroscopy. They showed that the MPL on the cathode side increased the water transport from the cathode to the anode; thus, the MPL decreased the water accumulation in the GDL on the cathode. Analytical studies describing the water saturation in the GDL without and with the MPL are also carried out. Wu et al. [10] implied that the boundary condition between the MPL and the GDL affected the water transport in the MPL by using a pore network model. Changes in the average water saturation are investigated

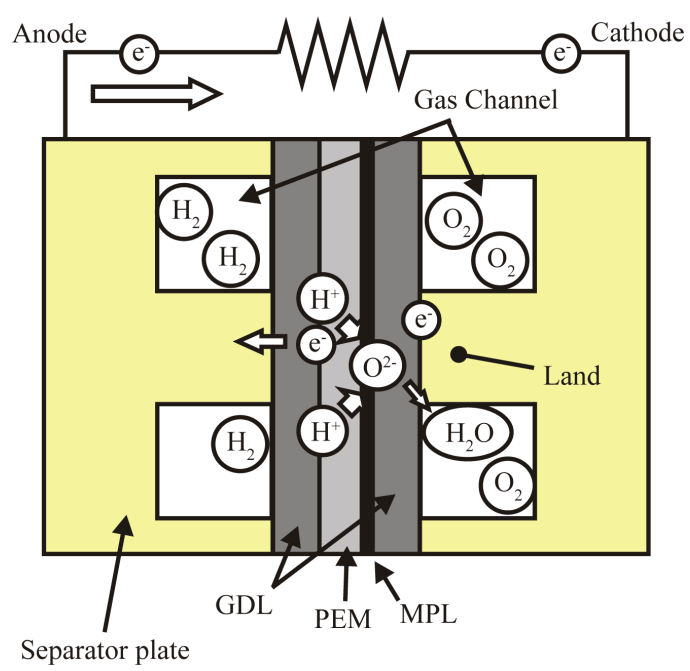

Figure 1. Schematic of a polymer electrolyte fuel cell. 
with different MPL and PTFE coating conditions by Santoro et al. [11]. They showed a relationship between the water flux on the cathode and the electrochemical characteristics. Attempts to improve the water transport in the GDL on the cathode by changing the MPL wettability and the structures have been reported [12]-[14]. However, the mechanisms are still not well understood because of the difficulty in measuring the water distribution in the PEFC.

Aoyama et al. [15] employed a freezing method for observing the water distribution in the MPL after PEFC operation. Bresciani et al. [16] compared water fluxes through the GDL without and with MPL conditions under PEFC operation. However, techniques for carrying out in-situ measurements of the water distribution in the GDL are limited. X-ray imaging has been employed for detailed observation of the water distributions in the GDL and MPL [8] [17]. However, it is difficult to observe the water distributions inside the metallic PEFC. Normally, a small hole or an observation window is required to reduce the X-ray attenuation in the materials. A neutron has a low attenuation coefficient in metals, but it is high in water. Hence, many researchers have attempted to measure water-transport phenomena and show the water distributions inside the PEFC by using neutron radiography [18]-[22]. LaManna et al. [23] measured the water distribution of a PEFC in the through-plane direction under steady-state conditions by using neutron radiography with a micro-channel plate system. Tabuchi et al. [24] compared the water distributions obtained by neutron radiography with the analytical results. However, in-situ measurements of the water distributions are still limited, and the transient change in the water distribution without and with the MPL during start-up has not been completely understood.

In this study, our goal is to investigate the transient change in the water distribution in an operating PEFC and the effect of the MPL on the water transport and cell performance using neutron radiography. Furthermore, one-dimensional water distributions in the GDL at the land and channel were calculated from the two-dimensional water distributions, and a comparison was carried out for the water distributions without and with the MPL.

\section{Experimental and Image-Processing Methods}

The fuel cell used in this research for visualization using neutron radiography as a nondestructive analytic technique is shown in Figure 2. The separators are made of gold-plated aluminum and have nine parallel gas channels with equal widths and depths of $1 \mathrm{~mm}$. It was expected that the water distributions in the GDL between the lands and the channels would be different, which might affect gas diffusion. Therefore, the authors selected parallel channels to visualize the difference in the water-accumulation processes in the GDL by the lands and channels.

A cross-sectional diagram of the PEFC is shown in Figure 3. A PEM was sandwiched between the GDLs and separators at the anode and cathode. The PEM was Nafion ${ }^{\circledR}$ NR-212 with a thickness of approximately $90 \mu \mathrm{m}$

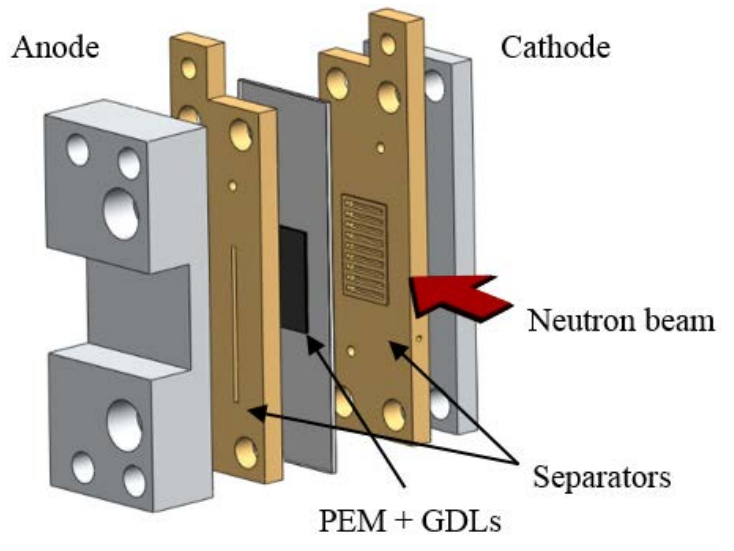

(a)

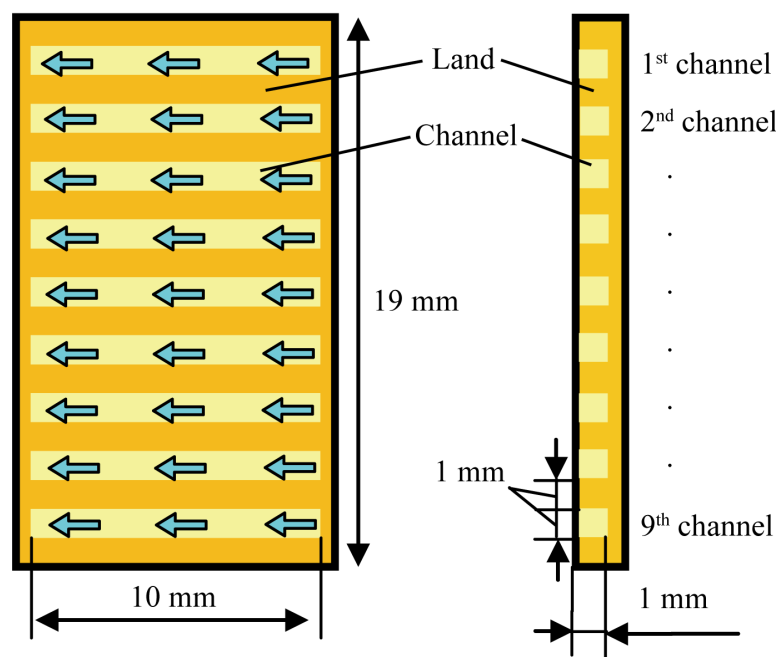

(b)

Figure 2. (a) Schematic of the visualized PEFC; (b) Geometry of the gas channel. 


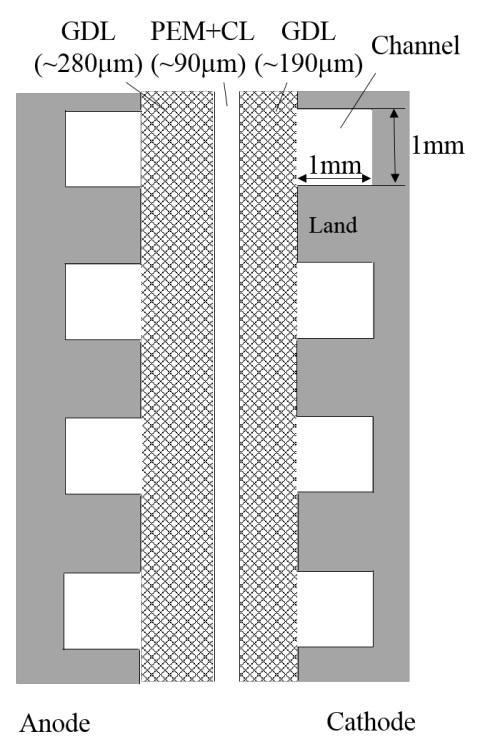

(a)

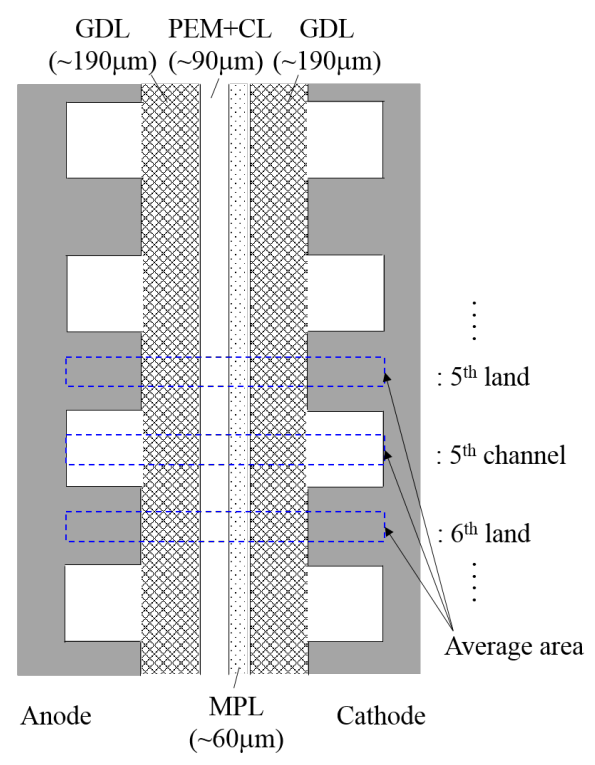

(b)

Figure 3. Schematics of the PEFC in the through-plane direction. (a) Without the MPL; (b) With the MPL.

having a catalyst layer (CL) on both the anode and cathode sides. The electrode area was $10 \times 19 \mathrm{~mm}^{2}$. The GDL was carbon paper (Toray Ind.) with thicknesses of $190 \mu \mathrm{m}$ at the cathode and $280 \mu \mathrm{m}$ at the anode without an MPL. When an MPL was used, it was placed between the catalyst layer and the GDL at the cathode, and the thickness of the GDL was $190 \mu \mathrm{m}$ on both the cathode and anode sides. The porosity of the GDL was 78\%. In order to observe the time series of the water distributions by using neutron radiography, the experiments were carried out at a current density $i=158 \mathrm{~mA} / \mathrm{cm}^{2}$. Furthermore, results at $i=316 \mathrm{~mA} / \mathrm{cm}^{2}$ were compared to show the effect of the water generation speed. The other experimental conditions included the following: a hydrogen flow rate of $28 \mathrm{~cm}^{3} / \mathrm{min}$ and an air flow rate of $66 \mathrm{~cm}^{3} / \mathrm{min}$ without humidification. The hydrogen and oxygen utilization was $7.5 \%$ at $i=158 \mathrm{~mA} / \mathrm{cm}^{2}$ and $15 \%$ at $i=316 \mathrm{~mA} / \mathrm{cm}^{2}$. The experiments were carried out at room temperature, and the temperature of the PEFC varied within the range of $30^{\circ} \mathrm{C}-35^{\circ} \mathrm{C}$.

Neutron radiography is based on the principle that the neutron attenuation is different in each material. The mass attenuation coefficient of water is much higher than many metals such as iron and aluminum. Hence, water accumulation in the PEFC made of metals can be confirmed from the brightness distribution in the radiograph. Assuming that the brightness of the radiograph is proportional to the beam intensity on the scintillator screen, which is the $x-y$ plane, the brightness distribution at time $t, S(x, y, t)$, is expressed as [25]

$$
S(x, y, t)=G(x, y) \exp \left(-\rho_{M} \mu_{m M} \delta_{M}(x, y)-\rho_{W} \mu_{m W} \delta_{W}(x, y, t)\right)+O(x, y, t)
$$

where $\rho$ is the density, $\mu_{m}$ is the mass attenuation coefficient, and $\delta$ is the thickness in the beam direction. $G$ is the gain and depends on the position due to the non-flatness of the initial beam intensity and of the sensitivity of the imaging system. $O$ is the offset caused by the dark current of the imaging system, scattering neutrons, and so on. The subscripts $M$ and $W$ represent the PEFC material and water, respectively. Here, the attenuation due to the gases is neglected because of their lower density than the others. As the $\delta_{W}$ changes with PEFC operation time, the accumulated water thickness during the operation can be derived from Equation (1) as

$$
\delta_{W}(x, y, t)-\delta_{W 0}(x, y)=\frac{1}{\rho_{W} \mu_{m W}} \ln \left(\frac{S_{0}(x, y)-O_{0}(x, y)}{S(x, y, t)-O(x, y, t)}\right)
$$

where $\delta_{W 0}, S_{0}$ and $O_{0}$ are the water thickness, brightness and offset distributions before the operation. Neutron scattering increases with water accumulation, and the offset changes the operation time. However, the effect of the scattering caused by the accumulated water was assumed to be small, and the offset was set at the constant of 
$O_{0}$ because the water accumulation during start-up is not significant. On the basis of Equation (2), image processing was applied to the radiographs to obtain the two-dimensional distributions of the water thickness along the neutron beam [2] [25]. Hence, the accumulated water thickness represents the increase in the water accumulation referenced to the thickness at 0 min.

The neutron radiography facility at the B4 port in the Kyoto University Reactor (KUR) was used in this study [26]. Figure 4 shows a schematic of the experimental system of the neutron radiography experiment. Neutrons enter from the side-view direction and were attenuated by the PEFC including the accumulated water. The transmitted neutrons were converted to visible rays using a scintillator screen, and the 16-bit gray-scale radiographs were taken using a cooled CCD camera (PIXIS 1024, Princeton Instruments) with an array of $1024 \times$ 1024 pixels and with a pixel size of $8.8 \mu \mathrm{m}$. The distance between the center of the fuel cell and the scintillator screen, $d$, was $35 \mathrm{~mm}$.

The neutron flux and parallelism of the neutron beam are important factors for neutron radiography. Using a higher neutron flux, a shorter exposure time of the camera can be set to obtain a radiograph with the same brightness. Therefore, the neutron flux and temporal resolution are linked to each other. The parallelism of the neutron beam affects image blurring and is defined by the neutron beam-port and the setting geometry of the measurement system. A collimator is generally used to improve the parallelism, which is evaluated by using the collimator ratio $L / D$, where $L$ is the distance between the aperture and the detector plane (scintillator), and $D$ is the collimator aperture [27]. The image blurring is proportional to $d \cdot D / L$. Hence, the image blurring decreases as $L / D$ increases. However, the neutron flux decreases as $L / D$ increases, and a longer measurement time is required to obtain a radiograph that results in a lower temporal resolution. In this experiment, we focus on the transient changes in the water distributions during start-up. Hence, the exposure time was $60 \mathrm{~s}$, during which the radiograph was obtained. The information is accumulated information about the water distribution in the throughplane direction of the PEFC every $60 \mathrm{~s}$ from the start of operation. Considering the brightness resolution of the radiograph, $L / D$ was set to 278 using a collimator with an aperture of $5 \mathrm{~mm}$. With these settings, the image blur reached approximately $125 \mu \mathrm{m}$. Furthermore, neutron scattering becomes marked with an increase in the water accumulation along the neutron beam, resulting in lower quantification of the measurement. Hence, vertical averaging in the GDL at the center region of the land and channel was performed for the $5^{\text {th }}$ land, $5^{\text {th }}$ channel, and $6^{\text {th }}$ land, as shown in Figure 3 to obtain the water distributions in the through-plane direction and to avoid the blurring and scattering neutron effects caused by water accumulation in the channels.

\section{Results and Discussion}

\subsection{Cell-Voltage Time Series}

Figure 5 shows a time series of the cell voltage for each experimental condition which were simultaneously measured with neutron radiography. The cell voltage with the MPL is higher than that without the MPL at the beginning of PEFC operation. It seems that the difference in the initial conditions of the MEAs, such as the

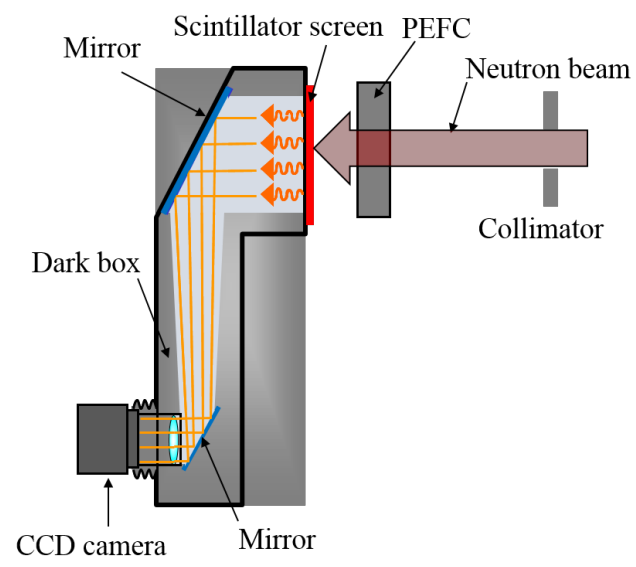

Figure 4. Schematic of the experimental system of the neutron radiograph. 


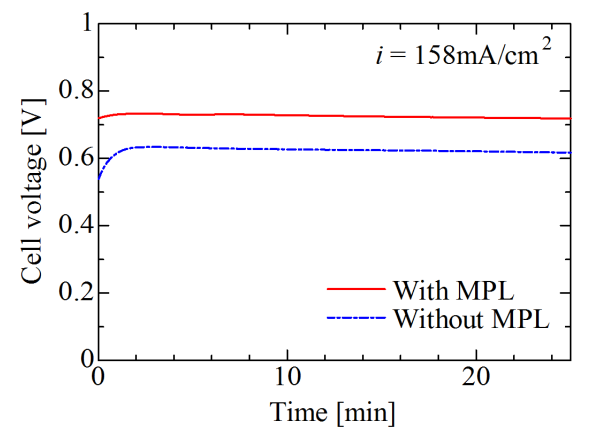

(a) $i=158 \mathrm{~mA} / \mathrm{cm}^{2}$

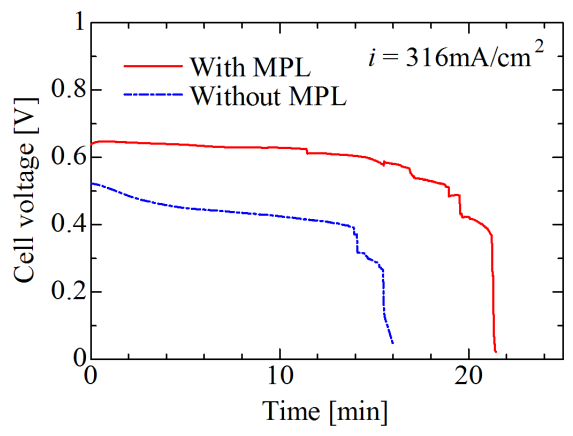

(b) $i=316 \mathrm{~mA} / \mathrm{cm}^{2}$

Figure 5. Time series of the cell voltage.

moisture content in the membrane, affects the resistance over potential of the PEFCs without and with the MPL. At $i=158 \mathrm{~mA} / \mathrm{cm}^{2}$, the cell voltages were almost constant, and the PEFCs without and with the MPL could both be operated for more than $25 \mathrm{~min}$. However, at $i=316 \mathrm{~mA} / \mathrm{cm}^{2}$, sudden decreases in the cell voltage occurred at $15 \mathrm{~min}$ without the MPL and at $21 \mathrm{~min}$ with the MPL. Furthermore, the voltage gradually decreased more over time without the MPL than with the MPL at $i=316 \mathrm{~mA} / \mathrm{cm}^{2}$. It can be seen that the difference in the cell voltages without and with the MPL is small for a lower current density, but it is much more apparent with an increase in the current density. Therefore, the MPL works effectively with an increase in the current density.

\subsection{Two-Dimensional Water Distributions}

Two-dimensional water distributions without and with the MPL at $i=158 \mathrm{~mA} / \mathrm{cm}^{2}$ are shown in Figure 6. It can be observed that water accumulation occurred as the operation time increased, as indicated by the blue color. The amounts of water in the GDL under the lands and channels are different from the earlier results. Water accumulation started in the GDL, and a large amount of water existed in the GDL under the lands as indicated by the red circle labeled A in Figure 6. The water-accumulation area extended to the GDL under the channels. Furthermore, with an increase in the operation time, the water evacuation from the GDL to the channels is confirmed to occur mainly around the land corners as indicated by red circle labeled B in Figure 6. Liquid droplets formed in the channels, and these grew in the channels as the operation time increased. No water evacuation from the channels to the outside of the PEFC was observed during the experiments. This is because the channels were parallel, and water evacuation to the outside of the channels was difficult. Figure 7 shows the results at $i=$ $316 \mathrm{~mA} / \mathrm{cm}^{2}$. It can be confirmed that the water-accumulation tendency is almost the same as that at $i=158$ $\mathrm{mA} / \mathrm{cm}^{2}$ without and with the MPL. Because of the higher current density, a higher water accumulation rate was confirmed, and it was almost doubled, which was linked to the current density.

The difference in the amount of water at $i=158 \mathrm{~mA} / \mathrm{cm}^{2}$ in the GDLs under the lands and under the channels apparently appears at $4 \mathrm{~min}$ with the MPL. However, the difference is confirmed at 8 min without the MPL. Hence, it is confirmed that the water accumulation rate in the GDL with the MPL was faster than that without the MPL. The start time for water evacuation from the GDL to the channel was earlier with the MPL than without the MPL, and the amount of water in the channels with the MPL was greater than that without the MPL at the same operation time. Droplets in the channel generally prevent gas supply to the channel, and water plugging in the channel causes sudden decreases in the cell voltage [2]. The PEFC could be operated for more than 25 min at $i=158 \mathrm{~mA} / \mathrm{cm}^{2}$ because the water accumulation in the channel was less than that at $i=316 \mathrm{~mA} / \mathrm{cm}^{2}$. However, the time at which the sudden decreases in the cell voltage occurred without the MPL was earlier than that with the MPL at $i=316 \mathrm{~mA} / \mathrm{cm}^{2}$. Therefore, it can be thought that the sudden decreases in the cell voltage were caused by water plugging in the channel as well as water accumulation in the GDL.

Water accumulation in the channel is confirmed after $12 \mathrm{~min}$ without the MPL and after 8 min with the MPL for $i=158 \mathrm{~mA} / \mathrm{cm}^{2}$ and after 6 min without the MPL and after 4 min with the MPL for $i=316 \mathrm{~mA} / \mathrm{cm}^{2}$. When water locally accumulates in the channel, the boundary condition between the GDL and the channel also changes. Hence, it is difficult to discuss the water distribution in the through-plane direction under the same conditions. In the next section, we discuss the distributions before water accumulates in the channel and eliminate the data after the time at which this occurs. 

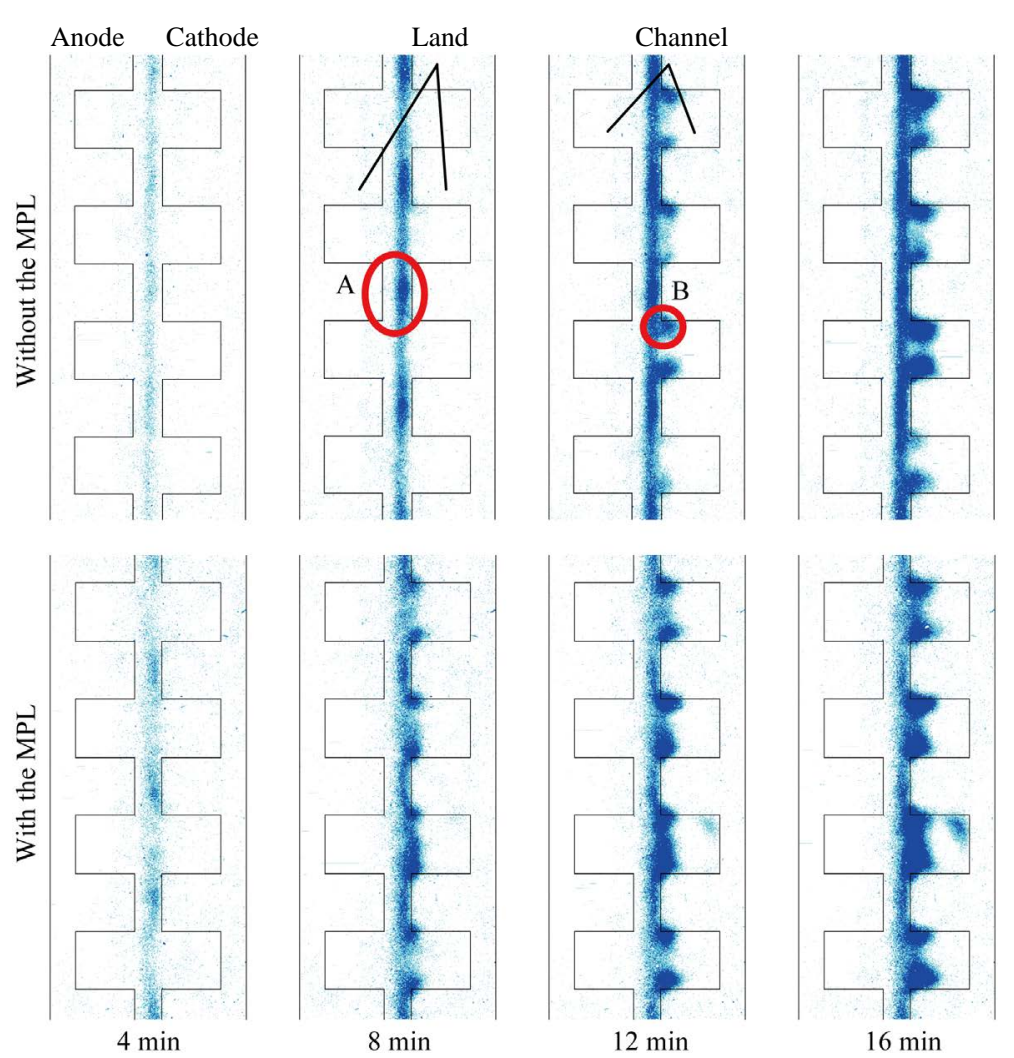

Figure 6. Two-dimensional water distributions $\left(i=158 \mathrm{~mA} / \mathrm{cm}^{2}\right)$.
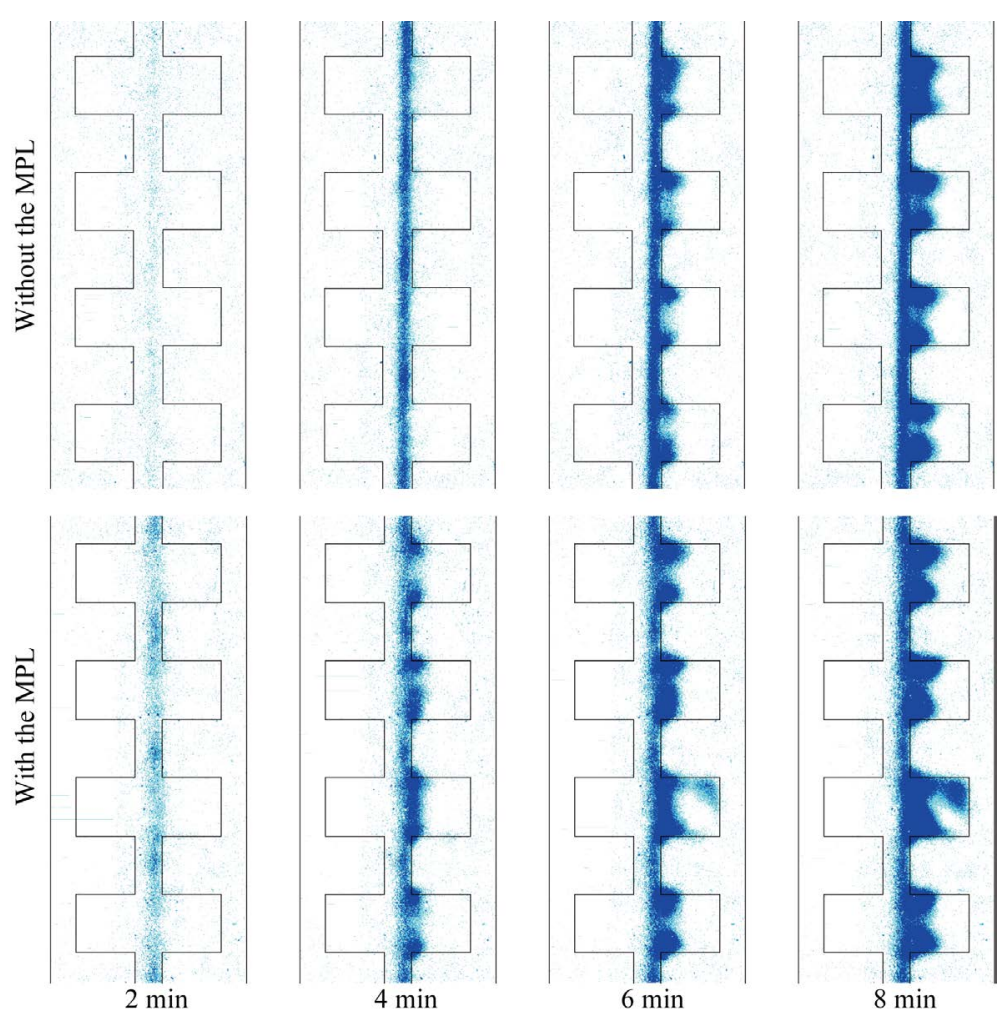

Figure 7. Two-dimensional water distributions $\left(i=316 \mathrm{~mA} / \mathrm{cm}^{2}\right)$. 


\subsection{Water Distributions in the Through-Plane Direction}

The one-dimensional water-distributions in the through-plane direction at $i=158 \mathrm{~mA} / \mathrm{cm}^{2}$ without and with the MPL are compared in Figure 8. The vertical axis indicates the water thickness along the neutron-beam direction, and the horizontal axis indicates the distance from the PEM center. The distributions are shown every 2 min for 2 - 8 min and every 4 min for 8 - 20 min.

The water accumulation in the GDL started after the beginning of PEFC operation. The maximum value appeared around the boundary between the catalyst layer and the GDL at the cathode without the MPL and between the MPL and the GDL with the MPL. This tendency indicates that a large amount of water condensation occurred around these regions. The average pore diameter in the MPL ranges from 0.1 to $0.5 \mu \mathrm{m}$ [1] and is much smaller than that in the GDL. It is difficult for condensation to occur in the MPL considering the mean free path of the water vapor. Thus, it is thought that the region of the maximum value changes in PEFCs without and with the MPL.

By comparing the results under the lands at $4 \mathrm{~min}$, it can be seen that the water-accumulation speed is faster with the MPL than without the MPL during the early period of PEFC operation. However, the maximum value of the water thickness without the MPL is greater than that with the MPL, as seen from the results at $8 \mathrm{~min}$. It
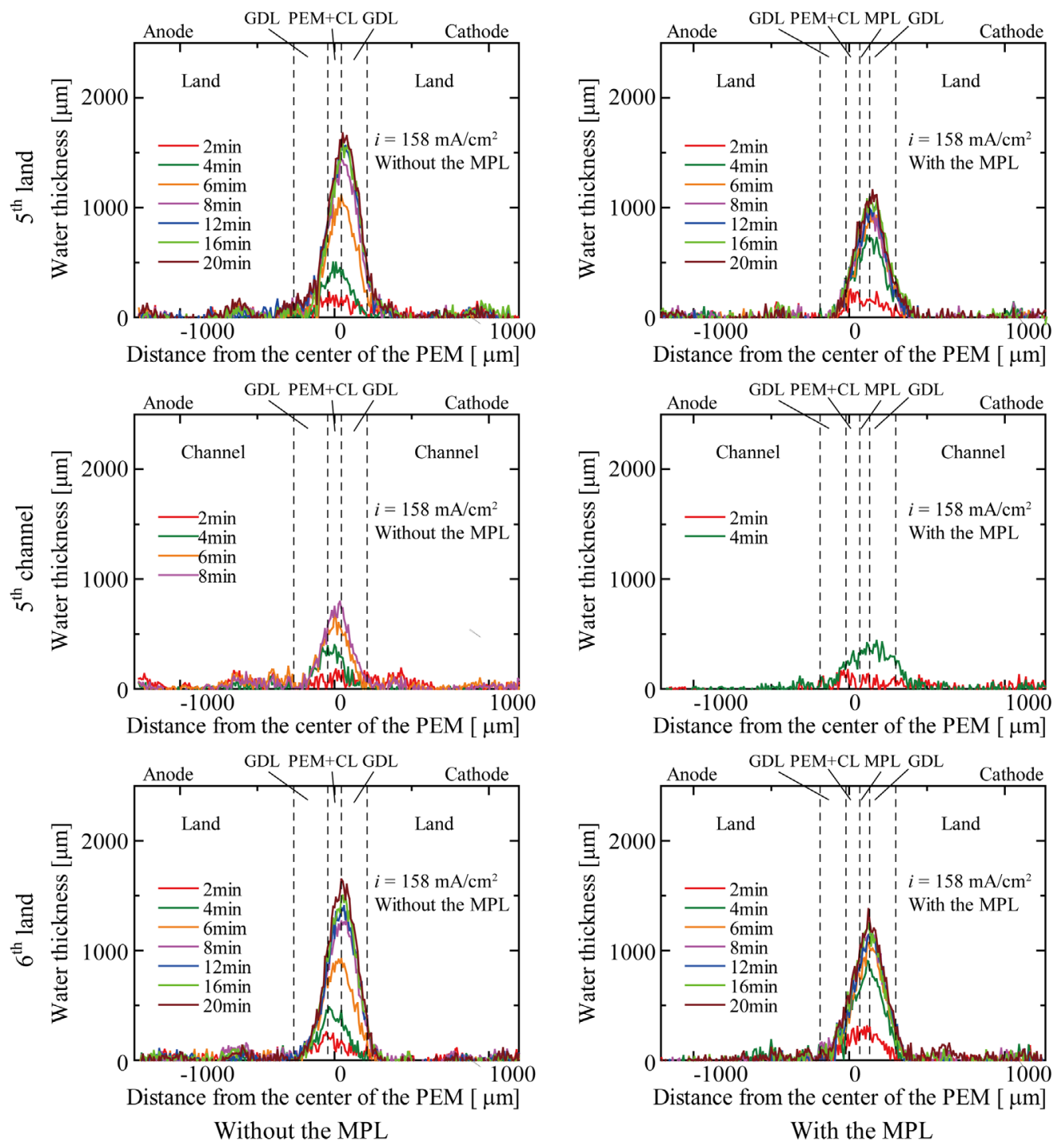

Figure 8. Water distributions in the through-plane direction $\left(i=158 \mathrm{~mA} / \mathrm{cm}^{2}\right)$. 
can be confirmed that water evacuation from the GDL to the channel started at 4 min with the MPL but not without the MPL. The water distributions are almost constant in the GDL under the land after 12 min without the MPL and after 6 min with the MPL. The values can be considered as the maximum water-accumulation values in the GDL and were approximately $1600 \mu \mathrm{m}$ without the MPL and $1000 \mu \mathrm{m}$ with the MPL. These results imply that the MPL decreases the water accumulation in the GDL at the cathode. As a result, water evacuation from the GDL to the channel started earlier with the MPL than without the MPL.

The maximum water thickness under the channel is smaller than that under the land at the same operation time until 8 min without the MPL and until 2 min with the MPL. Moreover, the water accumulation speed in the GDL under the land without the MPL between 6 to 8 min is small, and the water accumulation seems to reach an almost constant value. This means that water accumulation mainly occurred under the land, with little accumulation occurring in the GDL under the channel during PEFC start-up.

The graphs in Figure 9 illustrate the results for $i=316 \mathrm{~mA} / \mathrm{cm}^{2}$. The water distributions are shown every 1 min for 1 - 4 min and every 2 min for 4 - 10 min. The main tendencies are almost the same as those in the results for $i=158 \mathrm{~mA} / \mathrm{cm}^{2}$. The water distributions under the land are almost constant after 6 min without the MPL, and the maximum water thickness in the GDL is approximately $1600 \mu \mathrm{m}$. On the other hand, the distributions under the land are almost constant after 3 min with the MPL, and the maximum water thickness in the GDL is
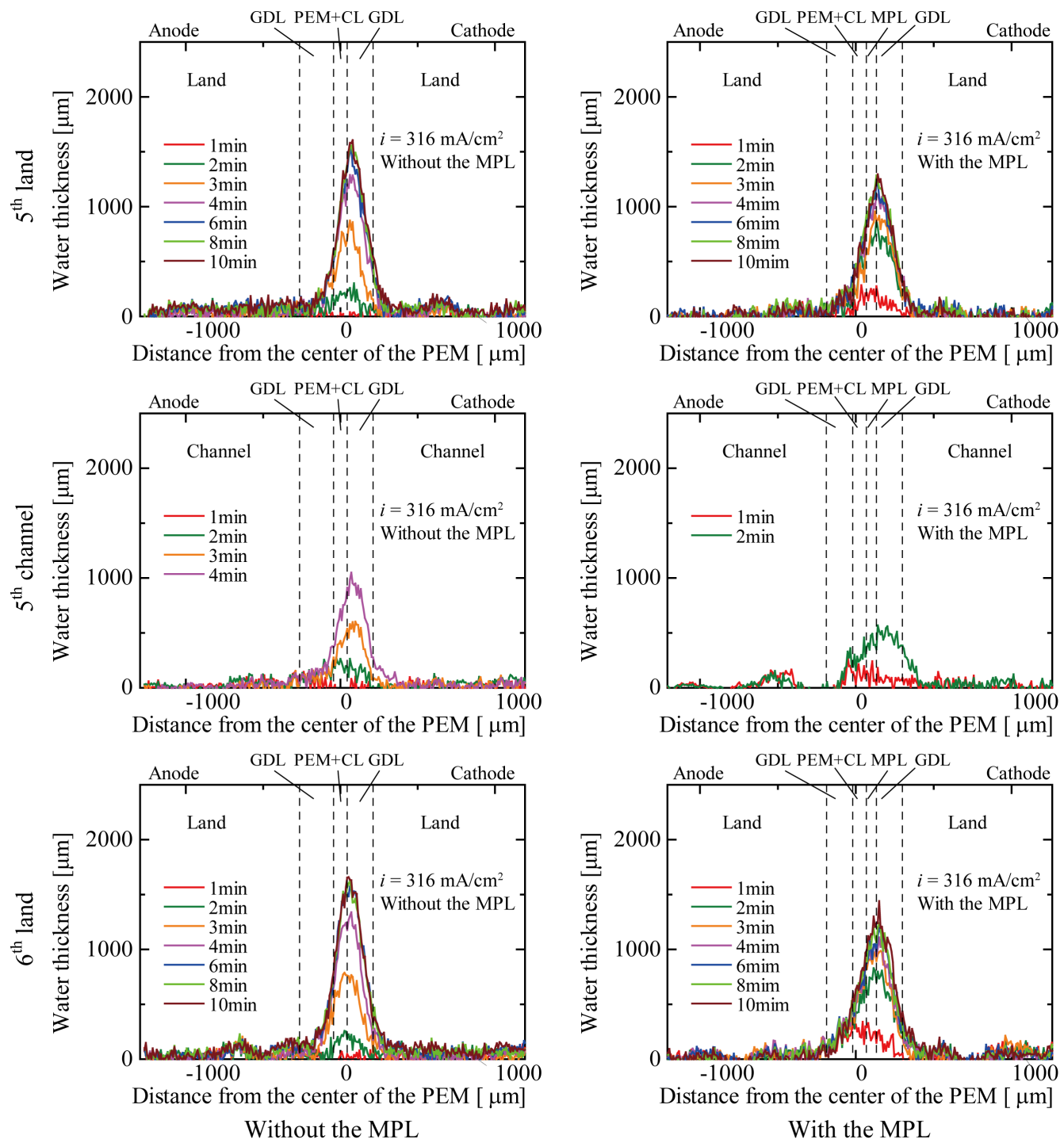

Figure 9. Water distributions in the through-plane direction $\left(i=316 \mathrm{~mA} / \mathrm{cm}^{2}\right)$. 
almost $1300 \mu \mathrm{m}$. The time for forming the constant distribution is almost half of the time at $i=158 \mathrm{~mA} / \mathrm{cm}^{2}$, i.e., the time is inversely proportional to the current density.

The main difference in the results for $i=158$ and $316 \mathrm{~mA} / \mathrm{cm}^{2}$ without the MPL is the water distributions in the GDL under the channel. It can be confirmed that a large amount of water accumulated in the GDL between 3 - $4 \mathrm{~min}$ for $i=316 \mathrm{~mA} / \mathrm{cm}^{2}$, although the difference in the water distribution between $6-8 \mathrm{~min}$ is small for $i=$ $158 \mathrm{~mA} / \mathrm{cm}^{2}$. Furthermore, the maximum value of the water thickness under the channel without the MPL at 8 $\min$ for $i=158 \mathrm{~mA} / \mathrm{cm}^{2}$ is lower than that at $4 \mathrm{~min}$ for $i=316 \mathrm{~mA} / \mathrm{cm}^{2}$. The cell voltage without the MPL rapidly decreased until $4 \mathrm{~min}$ and then gradually decreased after that. Hence, the difference in the water accumulation in the GDL under the channel seems to affect the concentration over potential around the region and decrease the cell voltage.

With increases in the current density, the maximum water thickness also increased without and with the MPL. However, the constant value of the maximum water thickness under the lands with the MPL was lower than that without the MPL. Hence, it is confirmed that the MPL reduced the water accumulation in the GDL, and the reduction improved the cell voltage. This effect appeared at $i=316 \mathrm{~mA} / \mathrm{cm}^{2}$ as sudden decreases in the cell voltage, and the PEFC with the MPL could operate for a longer time than that without the MPL.

\section{Conclusions}

To clarify the water-accumulation phenomena with the MPL, the visualization and measurement of the water distribution in the through-plane direction of a small fuel cell are carried out by using neutron radiography. The neutron flux and parallelism of the neutron beam are important factors for neutron radiography, and the collimator ratio, $L / D$, is set to 278 by using a collimator considering the temporal and spatial resolutions. Two-dimensional water distributions in the through-plane direction are visualized every $60 \mathrm{~s}$ during start-up, and it is shown that neutron radiography is effective for observing the transient change in the water distribution in the PEFC during start-up.

It is observed that the water accumulation in the GDL under the lands is greater than that under the channels during the early period of PEFC operation. Water evacuation from the GDL to the channel mainly occurs around the land corners. One-dimensional water distributions in the GDL at the land and channel are calculated from the obtained data, and the distributions without and with the MPL are compared. The water thickness has a maximum value around the boundary between the catalyst layer and the GDL without the MPL and between the MPL and the GDL with the MPL. The water accumulation rate in the GDL with the MPL is higher than that without the MPL during the early period of PEFC operation. However, the maximum water accumulation in the GDL under the lands without the MPL is higher than that with the MPL. The reduction in the water accumulation by using the MPL improves the cell voltage. The effect of the MPL for reducing the water accumulation becomes remarkable with an increase in the current density.

\section{Acknowledgements}

This work has been carried out in part under the Visiting Researchers Program of Kyoto University Research Reactor Institute.

\section{References}

[1] Li, H., Tang, Y.H., Wang, Z.W., Shi, Z., Wu, S.H., Song, D.T., Zhang, J.L., Fatih, K., Zhang, J.J., Wang, H.J., Liu, Z.S., Abouatallah, R. and Mazza, A. (2008) A Review of Water Flooding Issues in the Proton Exchange Membrane Fuel Cell. Journal of Power Sources, 178, 103-117. http://dx.doi.org/10.1016/j.jpowsour.2007.12.068

[2] Murakawa, H., Ueda, T., Yoshida, T., Sugimoto, K., Asano, H., Takenaka, N., Mochiki, K., Iikura, H., Yasuda, R. and Matsubayashi, M. (2009) Effect of Water Distributions on Performances of JARI Standard PEFC by Using Neutron Radiography. Nuclear Instruments and Methods in Physics Research A, 605, 127-130. http://dx.doi.org/10.1016/j.nima.2009.01.142

[3] Masuda, H., Yamamoto, A., Sasaki, K., Lee, S. and Ito, K. (2011) A Visualization Study on Relationship between Water-Droplet Behavior and Cell Voltage Appeared in Straight, Parallel and Serpentine Channel Pattern Cells. Journal of Power Sources, 196, 5377-5385. http://dx.doi.org/10.1016/j.jpowsour.2011.02.074

[4] Ahmadi, F. and Roshandel, R. (2014) Effects of Microhydrophobic Porous Layer on Water Distribution in Polymer Electrolyte Membrane Fuel Cells. Journal of Fuel Cell Science and Technology, 11, Article ID: 011004. 
http://dx.doi.org/10.1115/1.4025522

[5] Cho, J., Park, J., Oh, H., Min, K., Lee, E. and Jyoung, J.Y. (2013) Analysis of the Transient Response and Durability Characteristics of a Proton Exchange Membrane Fuel Cell with Different Micro-Porous Layer Penetration Thicknesses. Applied Energy, 111, 300-309. http://dx.doi.org/10.1016/j.apenergy.2013.05.022

[6] Markötter, H., Haußmann, J., Alink, R., Tötzke, C., Arlt, T., Klages, M., Riesemeier, H., Scholta, J., Gerteisen, D., Banhart, J. and Manke, I. (2013) Influence of Cracks in the Microporous Layer on the Water Distribution in a PEM Fuel Cell Investigated by Synchrotron Radiography. Electrochemistry Communications, 34, 20-24. http://dx.doi.org/10.1016/j.ijhydene.2012.01.141

[7] Alink, R., Haußmann, J., Markötter, H., Schwager, M., Manke, I. and Gerteisen, D. (2013) The Influence of Porous Transport Layer Modifications on the Water Management in Polymer Electrolyte Membrane Fuel Cells. Journal of Power Sources, 233, 358-368. http://dx.doi.org/10.1016/j.jpowsour.2013.01.085

[8] Deevanhxay, P., Sasabe, T., Tsushima, S. and Hirai, S. (2013) Observation of Dynamic Liquid Water Transport in the Microporous Layer and Gas Diffusion Layer of an Operating PEM Fuel Cell by High-Resolution Soft X-Ray Radiography. Journal of Power Sources, 230, 38-43. http://dx.doi.org/10.1016/j.jpowsour.2012.11.140

[9] Kim, T., Lee, S. and Park, H. (2010) A Study of Water Transport as a Function of the Micro-Porous Layer Arrangement in PEMFCs. International Journal of Hydrogen Energy, 35, 8631- 8643. http://dx.doi.org/10.1016/j.ijhydene.2010.05.123

[10] Wu, R., Zhu, X., Liao, Q., Wang, H., Ding, Y.D., Li, J. and Ye, D.D. (2010) A Pore Network Study on the Role of Micro-Porous Layer in Control of Liquid Water Distribution in Gas Diffusion Layer. International Journal of Hydrogen Energy, 35, 7588-7593. http://dx.doi.org/10.1016/j.ijhydene.2010.04.126

[11] Santoro, C., Agrios, A., Pasaogullari, U. and Li, B.K. (2011) Effects of Gas Diffusion Layer (GDL) and Micro Porous Layer (MPL) on Cathode Performance in Microbial Fuel Cells (MFCs). International Journal of Hydrogen Energy, 36, 7588-7593. http://dx.doi.org/10.1016/j.ijhydene.2011.07.030

[12] Wang, X.L., Zhang, H.M., Zhang, J.L., Xu, H.F., Zhu, X.B., Chen, J. and Yi, B.L. (2006) A Bi-Functional Micro-Porous Layer with Composite Carbon Black for PEM Fuel Cells. Journal of Power Sources, 162, 474-479. http://dx.doi.org/10.1016/j.jpowsour.2006.06.064

[13] Tang, H.L., Wang, S.L., Pan, M. and Yuan, R.Z. (2007) Porosity-Graded Micro-Porous Layers for Polymer Electrolyte Membrane Fuel Cells. Journal of Power Sources, 166, 41-46. http://dx.doi.org/10.1016/j.jpowsour.2007.01.021

[14] Chun, J.H., Park, K.T., Jo, D.H., Lee, J.Y., Kim, S.G., Park, S.H., Lee, E.S., Jyoung, J.-Y. and Kim, S.H. (2011) Development of a Novel Hydrophobic/Hydrophilic Double Micro Porous Layer for Use in a Cathode Gas Diffusion Layer in PEMFC. International Journal of Hydrogen Energy, 36, 8422-8428. http://dx.doi.org/10.1016/j.ijhydene.2011.04.038

[15] Aoyama, Y., Suzuki, K., Tabe, Y. and Chikahisa, T. (2014) Observation of Water Transport in the Micro-Porous Layer of a Polymer Electrolyte Fuel Cell with a Freezing Method and Cryoscanning Electron Microscope. Electrochemistry Communications, 41, 72-75. http://dx.doi.org/10.1016/j.elecom.2013.12.029

[16] Bresciani, F., Casalegno, A., Varisco, G. and Marchesi, R. (2014) Water Transport into PEFC Gas Diffusion Layer: Experimental Characterization of Diffusion and Permeation. International Journal of Energy Research, 38, 602-613. http://dx.doi.org/10.1002/er.3065

[17] Haußmann, J., Markötter, H., Alink, R., Bauder, A., Dittmann, K., Manke, I. and Scholta, J. (2013) Synchrotron Radiography and Tomography of Water Transport in Perforated Gas Diffusion Media. Journal of Power Sources, 239, 611622. http://dx.doi.org/10.1016/j.jpowsour.2013.02.014

[18] Satija, R., Jacobson, D.L., Arif, M. and Werner, S.A. (2004) In Situ Neutron Imaging Technique for Evaluation of Water Management Systems in Operating PEM Fuel Cells. Journal of Power Sources, 129, 238-245. http://dx.doi.org/10.1016/j.jpowsour.2003.11.068

[19] Ludlow, D.J., Calebrese, C.M., Yu, S.H., Dannehy, C.S., Jacobson, D.L., Hussey, D.S., Arif, M., Jensen, M.K. and Eisman, G.A. (2006) PEM Fuel Cell Membrane Hydration Measurement by Neutron Imaging. Journal of Power Sources, 162, 271-278. http://dx.doi.org/10.1016/j.jpowsour.2006.06.068

[20] Yasuda, R., Nittoh, K., Konagai, C., Shiozawa, M., Takenaka, N., Asano, H., Murakawa, H., Sugimoto, K., Nojima, T., Hayashida, H., Iikura, H., Sakai, T. and Matsubayashi, M. (2011) Evaluation of Water Distribution in a Small Operating Fuel Cell Using Neutron Color Image Intensifier. Nuclear Instruments and Methods in Physics Research Section A, 651, 268-272. http://dx.doi.org/10.1016/j.nima.2011.01.175

[21] Murakawa, H., Wada, D., Sugimoto, K., Asano, H., Takenaka, N. and Yasuda, R. (2011) Measurements of Water Distribution in Through-Plane Direction of PEFC by Using Neutron Radiography. Nuclear Instruments and Methods in Physics Research Section A, 651, 286-289. http://dx.doi.org/10.1016/j.nima.2010.12.047

[22] Murakawa, H., Ueda, T., Sugimoto, K., Asano, H. and Takenaka, N. (2011) Measurement of Water Thickness in PEM 
Fuel Cells and Analysis of Gas Velocity Distributions. Nuclear Instruments and Methods in Physics Research Section A, 651, 290-296. http://dx.doi.org/10.1016/j.nima.2010.12.046

[23] LaManna, J.M., Chakraborty, S., Gagliardo, J.J. and Mench, M.M. (2014) Isolation of Transport Mechanisms in PEFCs Using High Resolution Neutron Imaging. International Journal of Hydrogen Energy, 39, 3387-3396. http://dx.doi.org/10.1016/j.ijhydene.2013.12.021

[24] Tabuchi, Y., Shinomi, T., Aoki, O., Kubo, N. and Shinohara, K. (2010) Effects of Heat and Water Transport on the Performance of Polymer Electrolyte Membrane Fuel Cell under High Current Density Operation. Electrochimica Acta, 56, 352-360.http://dx.doi.org/10.1016/j.electacta.2010.08.070

[25] Takenaka, N., Asano, H., Fujii, T. and Matsubayashi, M. (1998) Three-Dimensional Visualization of Void Fraction Distribution in Steady Two-Phase Flow by Thermal Neutron Radiography. Nuclear Engineering and Design, 187, 203-212. http://dx.doi.org/10.1016/S0029-5493(98)00197-6

[26] Saito, Y., Sekimoto, S., Hino, M. and Kawabata, Y. (2011) Development of Neutron Radiography Facility for Boiling Two-Phase Flow Experiment in Kyoto University Research Reactor. Nuclear Instruments and Methods in Physics Research Section A, 651, 36-41. http://dx.doi.org/10.1016/j.nima.2011.01.103

[27] Hayashida, H., Segawa, M., Yasuda, R., Iikura, H., Sakai, T. and Matsubayashi, M. (2009) Development of MultiPinhole Collimator for Large Imaging Area with High Spatial Resolution. Nuclear Instruments and Methods in Physics Research Section A, 605, 77-80. http://dx.doi.org/10.1016/j.nima.2009.01.163 